\title{
Developing a Model of Adjusting Speed and Distance between Vehicle to Vehicle with Fuzzy Logic
}

\author{
${ }^{* 1}$ M. Fatih ADAK \\ ${ }^{* 1}$ Faculty of Computer and Information Sciences, Department of Computer Engineering Sakarya University, Turkey
}

\begin{abstract}
Today, inter-vehicle communication is a popular issue and the presence of driverless vehicles is increasing day by day. Even in today's vehicles, many decisions are made by the control center of the vehicles instead of the driver. Therefore, the studies to be carried out on the automatic control of vehicles has major importance. In this study, a model was developed to adjust the distance and speed of the vehicle with the vehicle in front according to the conditions by using fuzzy logic. Prototype work was done by using arduino micro controller on model vehicle. Tests carried out under different road conditions have achieved an average success of nearly $80 \%$. For automatic control systems, this ratio is quite good. This study suggested a model that would provide convenience to drivers especially in stopand-go traffic. The results showed that using fuzzy logic model in vehicle control systems will bring high success.
\end{abstract}

Key words: vehicle control, fuzzy logic, automatic assistance

\section{Özet}

Günümüzde araçlar arası iletişim popüler bir konu olmasının yanında sürücüsüz araçların varlığı her geçen gün artmaktadır. Günümüz araçlarında bile sürücü yerine verilen birçok karar araçların kontrol merkezi tarafından verilmektedir. Dolayısıyla araçların otomatik kontrol üzerinde yapılacak çalışmalar büyük önem kazanmaktadır. Bu çalışmada öndeki araç ile mesafeyi ve aracın hızını koşullara göre ayarlayan ve bu işlemi gerçekleştirmek için bulanık mantık kullanan bir model geliştirilmiştir. Prototip çalışması maket araç üzerinde arduino mikro denetleyicisi kullanılarak yapılmıştır. Farklı yol koşullarında yapılan testlerde \%80'e yaklaşan ortalama bir başarı elde edilmiştir. Otomatik kontrol sistemleri için bu oran oldukça iyi bir düzeydir. Bu çalışma özellikle dur-kalk trafiğinin olduğu yerlerde sürücülere kolaylık sağlayacak bir model önermiştir. Elde edilen sonuçlar, araç kontrol sistemlerinde bulanık mantık modelini kullanmanın yüksek başarı getireceğini göstermiştir.

Anahtar Kelimeler: araç kontrol, bulanık mantık, otomatik asistan

\section{Giriş}

Endüstri 4.0 ve teknolojilerinin her alanda olduğu gibi otomotiv sektöründe de hakim olması beraberinde birçok çalışmayı da bu alana yoğunlaştırmıştır. Araçlar arası iletişim, araç sürücü etkileşimi ve aracın kendi içerisinde birçok kararı vermesi gibi günümüzde bile aktif örneklerinin görülmesi mümkündür. Bu çalışmada aracın öndeki araca göre mesafe ve hızını ayarlayan bir model geliştirilmiştir. Bu modelde bulanık mantık kullanılmıştır. Araçlar arası iletişim ve akıllı ulaşım sistemleri konusunda yapılmış olan birçok çalışma bulunmaktadır.

*Corresponding author: Address: Faculty of Computer and Information Sciences, Department of Computer Engineering Sakarya University, Turkey. E-mail address: fatihadak@ sakarya.edu.tr, Phone: +902642957049 
Örneğin Lee ve arkadaşları kavşaklardaki araçların yönetimi için bir kontrol algoritması geliştirmişlerdir. Bütün araçlar kendiliğinden hareket etmektedir [1].

Yine diğer bir çalışmada araçlar için risk değerlendirmesinin ve hareket tahmininin yapıldığı akıllı bir sistem geliştirilmiştir. Araç hareketi bulunduğu ortam ve duruma göre belirlemektedir [2]. Araçlar arası mesafenin ayarlanmasında görüntü işleme tekniklerinin kullanıldığı bir çalışmada öndeki aracın plaka tespiti yapıp mesafeyi ölçmektedir [3]. Öndeki araca olan mesafeye ve aracın kendi hızına göre şerit değiştirip değiştirmeme kararını sınırlı optimizasyon yöntemiyle başarılı bir şekilde vermişlerdir [4]. Yine benzer bir çalışmada şerit değiştirme yöntemi olarak karar destek sistemleri kullanılmıştır [5]. Trafik kontrol sistemlerinde ve akıllı araç yönlendirmelerinde kullanılan yöntemlere, olay tabanlı tümevarım, bulanık mantık, kural tabanlı sistemler ve sinirsel ağlar gibi öğrenmeye dayalı örnekler verilebilir [6]. Fakat trafik gibi hızlı kararların verilmesi gerektiği yerlerde kural tabanlı yöntemlerin daha elverişli olduğu söylenebilir. Dolayısıyla bu çalışmada hızlı sonuçlar elde edebilmek için bulanık mantık kullanılmıştır. Örneğin gerçek zamanlı çarpışmanın önlenmesi için Heo ve arkadaşları Bulanık mantık kullanmışlardır [7]. Diğer bir çalışmada bulanık mantık kontrolü ile iki araç arasında güvenli mesafeyi koruyarak çarpışma riskini düşürmeye çalışmışlardır. Yapılan testlerde hata payının oldukça düştüğü görülmektedir [8]. Dur kalk trafiğinin olduğu şehirler için modellenmiş bir çalışmada Genetik algoritma tabanlı bulanık mantık kullanılarak öndeki araca olan mesafeye göre aracın hızı adaptif olarak ayarlanmaktadır [9]. Benzer diğer bir çalışmada yine Genetik algoritma tabanlı bulanık mantık kullanılarak uygun hızın bulunması sağlanmıştır [10]. Gerçek zamanlı ve hızlı çalışacak bu gibi sistemlerde algoritmanın yavaş karar vermesi hayati risk taşıyan durumların oluşmasına neden olabilir. Dolayısıyla Genetik algoritma gibi zaman alabilecek algoritmalardan bu gibi sistemlerde uzak durulmalıdır. Elektrikli araçlar baz alınarak yapılan bir çalışmada mesafe kontrolü bulanık mantık kullanılarak yapılmış ve bizim çalışmamıza benzer olarak belli bir mesafeden sonrası dikkate alınmıştır. Simülasyon sonuçlarının bu şekilde bir yaklaşımın başarılı olduğunu göstermektedir [11]. Yine çarpışmanın önlenmesi adına kullanılan bulanık modelde girdi olarak engel bilgisi, aracın hızı ve açısal hata alınıp vites ve hız ayarlanmaktadır [12]. Görüldüğü üzere bulanık mantık özellikle araç kontrol sistemlerinde başarılı sonuçlar vermektedir. Bu çalışmada çok yoğun veya yoğun trafikte, öndeki araca göre hızını ve mesafesini ayarlayacak kontrolcü için bulanık mantık modülü geliştirilmiştir. Bu çalışma şu şekilde organize edilmiştir. Bölüm 2'de kullanılan materyal ve metot anlatılmış. Bölüm 3.'te farklı senaryolardan elde edilen sonuçlar listelenmiş sonuncu bölümde de çalışmanın genel sonuçları verilmiştir.

\section{Materyal ve Metot}

Bu çalışmada arduino ile gerçekleştirilen 4 tekerli araçlardan öndeki aracı takip eden arkadaki araç için belli bir mesafeden sonra hız ve mesafe ayarlaması yapan bulanık bir model geliştirilmiştir. Bu bulanık model aracın hızı, öndeki araç ile olan mesafe ve yol durumu olmak üzere 3 adet girdi almaktadır. Bulanık kurallardan geçen bu bilgiler son olarak durulama metodu ile ortalama hız hesaplanmakta ve aracın bu hız ile gitmesi sağlanmaktadır. Modelin özetlendiği durum Şekil 1.'de verilmiştir. Mesafe tehlikeli kısma girdiği an araç frenleme yapmaktadır. Tehlikeli kısımdan çıktığı durumda da aracın hızı arttırılmaktadır. 


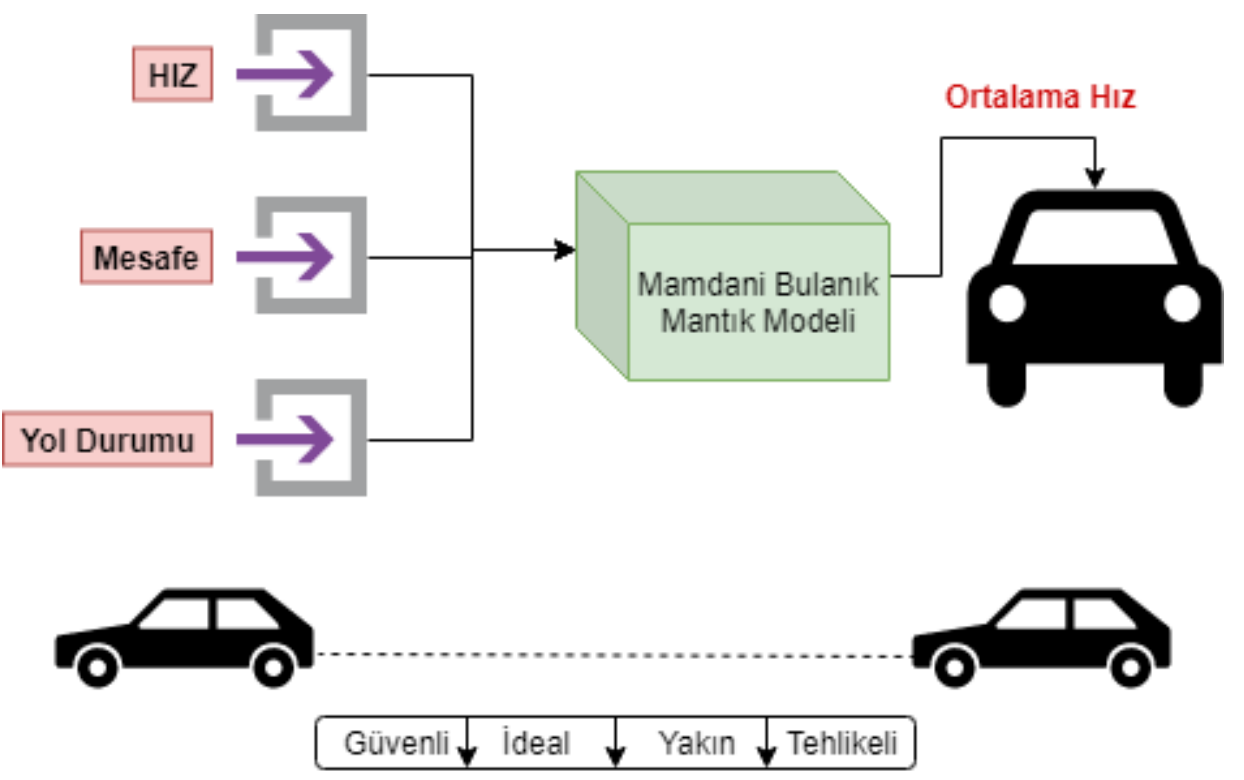

Şekil 1. Araçta kullanılan bulanık model

Mamdani modelin kullanıldığı bulanık mantıkta 3 girdiye karşılık gelen üyelik fonksiyonları ve bir çıktıya karşılık gelen üyelik fonksiyonu Şekil 2.'de verilmiştir. Mesafe girdisinde ikisi yamuk biri üçgen olmak üzere 3 adet üyelik fonksiyonu kullanılmıştır. Mesafe girdisi, yakın, uzak ve ideal olacak şekilde dilsel değişkenler kullanılmıştır. Hız girdisinde üçü yamuk biri üçgen olmak üzere 4 adet üyelik fonksiyonu kullanılmıştır. Hız girdisi, yavaş, normal, hızlı, çok hızlı olacak şekilde dilsel değişkenler bulunmaktadır. Frenleme mesafesinde önemli etkenlerden biri yol durumudur. Yağışlı bir yolda durma mesafesi iki katına çıkar. Bu durum göz önünde bulundurulmuş ve yol durumu isminde bir girdi modele eklenmiştir. Çıktı üyelik fonksiyonları aynı hız girdisinde olduğu gibidir. Durulama yöntemi olarak alan merkezi kullanılmıştır. Mamdani modelde toplamda 36 adet bulanık kural kullanılmıştır. Bütün bulanık kuralların ağırlık derecesi birdir.
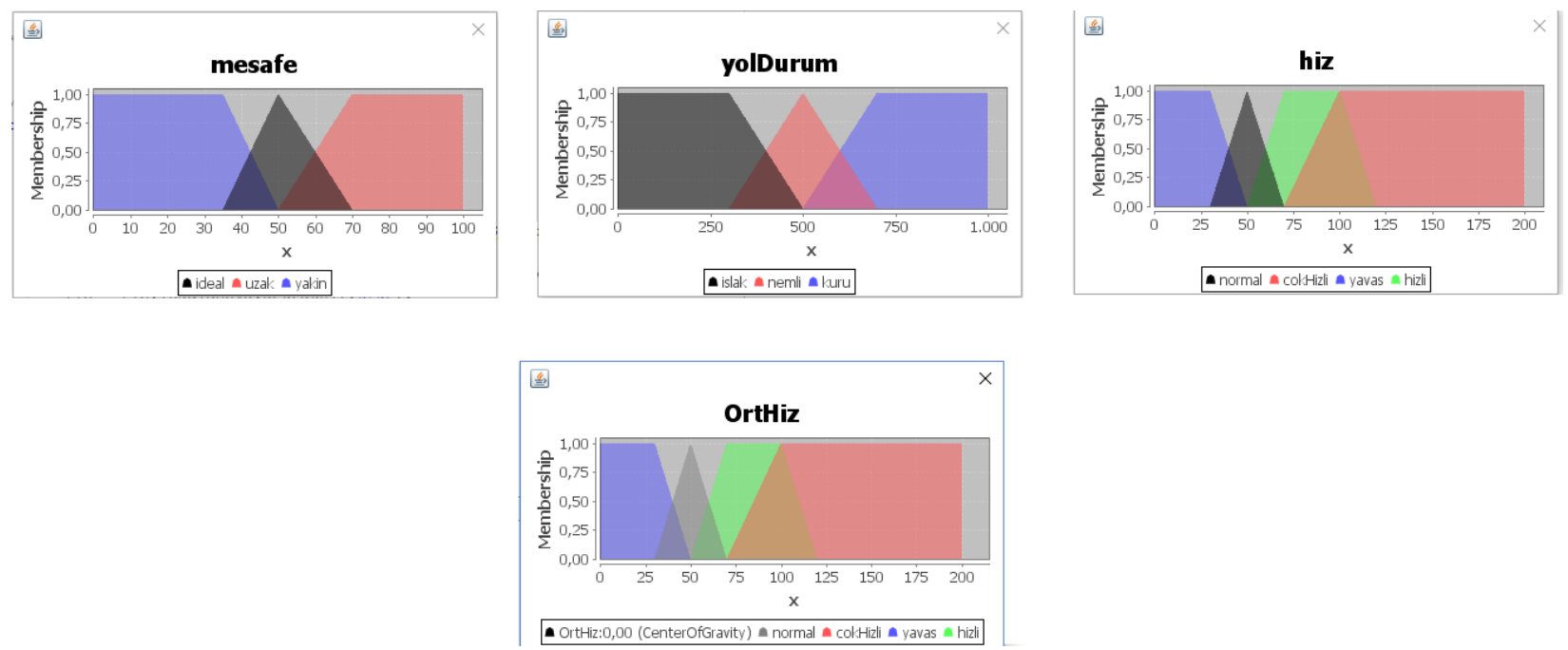

Şekil 2. Araçta kullanılan bulanık model 


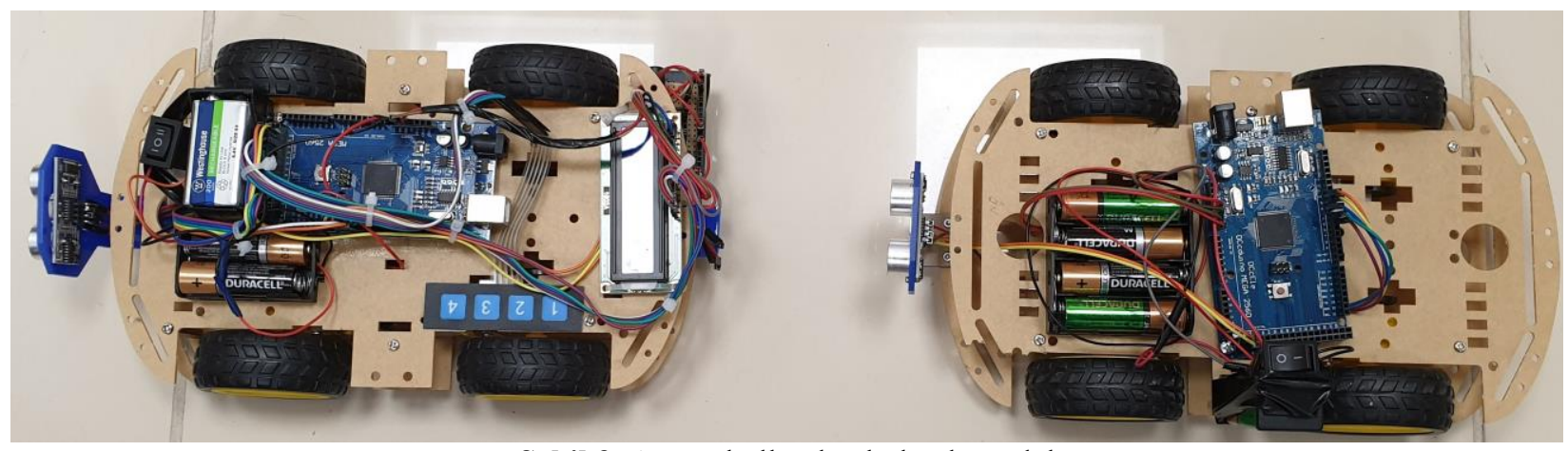

Şekil 3. Araçta kullanılan bulanık model

\section{Bulgular}

Geliştirilen prototip Şekil 3.'te verilmiştir. Bu prototip farklı yol durumlarında çalıştırılarak testler uygulanmıştır. Elde edilen sonuçlar Tablo 1.'de verilmiştir. Başarı oranının yol durumunun kuru ve trafik durumunun hafif olduğu zamanda en yüksek olduğu görülmektedir. Başarı durumu yolun ıslak olması ile düşmeye başlamış hem ıslak hem de trafik aşırı yoğunsa en düşük performansı göstermiştir. Fakat bu gibi sistemlerde Çok kötü hava koşullarında otomatik çalışan sistem devre dışı bırakılmalıdır. Bunun dışında senaryoların ortalama başarı oranı $\% 80$ civarıdır ve bu oran yüksek bir oran olarak kabul edilebilir. Ayrıca araç üzerine ekstra sensörler yerleştirilerek hava koşullarının çok kötü olduğu durumlarda bile başarı oranı arttırılabilir.

Tablo 1. Geliştirilen prototip üzerinde yapılan denemeler ve başarı sonuçları

\begin{tabular}{cccc}
\hline Yol Durumu & Trafik Durumu & Deneme Sayıs1 & Başarı Oran1 \\
\hline Kuru & Hafif & 10 & $\% 92$ \\
Kuru & Orta & 10 & $\% 87$ \\
Kuru & Yoğun & 10 & $\% 75$ \\
Islak & Hafif & 10 & $\% 88$ \\
Islak & Orta & 10 & $\% 73$ \\
Islak & Yoğun & 10 & $\% 64$ \\
\hline
\end{tabular}

\section{Sonuçlar}

Öndeki araca göre hız ve mesafe ayarlayan ve bu işlemi bulanık mantık ile gerçekleştiren bir prototip araç yapılmıştır. Bu araç çeşitli senaryolar kurularak test edilmiş ve farklı yol ve trafik durumlarında başarılı sonuçlar vermiştir. Gerçek zamanlı ve hızlı çalışma gerektiren bu gibi ortamlarda gecikme tehlikeli sonuçlar ile sonlanabilir. Kullanılan bulanık mantık modelinin anlık çok hızlı tepki verdiği ve bu gibi sistemlerde rahatça kullanılabileceği görülmüştür. Artık çevremizde yavaş yavaş göreceğimiz otomatik pilotlu araçlar için bu gibi çalışmalarda elde edilen yüksek doğruluk oranlı sonuçlar önemlidir. Bu çalışmada elde edilen başarılı sonuçlar bulanık mantık modelinin araçlarda otomatik pilot alanına girebilecek herhangi bir uygulamada kullanılabileceği ve gelecekte belki de çok sık kullanılacağını göstermiştir. 


\section{References}

[1] J. Lee, B. Park, Development and Evaluation of a Cooperative Vehicle Intersection Control Algorithm Under the Connected Vehicles Environment, IEEE Trans. Intell. Transp. Syst. 13 (2012) 81-90. doi:10.1109/TITS.2011.2178836.

[2] S. Lefèvre, D. Vasquez, C. Laugier, A survey on motion prediction and risk assessment for intelligent vehicles, Robomech J. 1 (2014) 1-14.

[3] J. Phelawan, P. Kittisut, N. Pornsuwancharoen, A new technique for distance measurement of between vehicles to vehicles by plate car using image processing, Procedia Eng. 32 (2012) 348-353. doi:10.1016/j.proeng.2012.01.1278.

[4] Y. Luo, Y. Xiang, K. Cao, K. Li, A dynamic automated lane change maneuver based on vehicle-to-vehicle communication, Transp. Res. Part C Emerg. Technol. 62 (2016) 87-102. doi:10.1016/j.trc.2015.11.011.

[5] M. Tideman, M.C. van der Voort, B. van Arem, A new scenario based approach for designing driver support systems applied to the design of a lane change support system, Transp. Res. Part C Emerg. Technol. 18 (2010) 247-258. doi:10.1016/j.trc.2009.09.001.

[6] J. Hellendoorn, B. De Schutter, L.D. Baskar, Z. Papp, Traffic control and intelligent vehicle highway systems: a survey, IET Intell. Transp. Syst. 5 (2011) 38-52. doi:10.1049/ietits.2009.0001.

[7] S.-W. Heo, T.H. Park, Real-time Collision Avoidance Motion Planning using Vehicle Lateral Angular Velocity Constraints, J. Inst. Control. Robot. Syst. 25 (2019) 170-179. doi:10.5302/J.ICROS.2019.18.0182.

[8] S.M. Mohtavipour, M. Mollajafari, A. Naseri, A guaranteed-comfort and safe adaptive cruise control by considering driver's acceptance level, Int. J. Dyn. Control. 7 (2019) 966-980. doi:10.1007/s40435-018-0500-5.

[9] S. Paul Sathiyan, S. Suresh Kumar, A. Immanuel Selvakumar, Optimized Fuzzy Logic-Based Adaptive Cruise Control Vehicle for Urban and Highway Driving Patterns, in: Emerg. Res. Comput. Information, Commun. Appl., Springer Singapore, Singapore, 2016: pp. 319-331. doi:10.1007/978-981-10-0287-8_30.

[10] S. SATHIYAN, S. SURESH KUMAR, A.I. SELVAKUMAR, Segmented Fuzzy Logic Controller For Vehicle Following With Optimised Rule Base, J. Theor. Appl. Inf. Technol. 57 (2013) 7-15.

[11] X. Zhang, A. Wang, J. Chen, M. Zhu, Distance control of pure electric vehicle based on fuzzy control, J. JIangsu Univ. Sci. Eidtion). 40 (2019) 524-530.

[12] Z. Liu, Y. Zhang, C. Yuan, L. Ciarletta, D. Theilliol, Collision Avoidance and Path Following Control of Unmanned Aerial Vehicle in Hazardous Environment, J. Intell. Robot. Syst. 95 (2019) 193-210. doi:10.1007/s10846-018-0929-y. 